\title{
Erratum to: Successful Emergent Coronary Thrombolysis in a Neonate with Kawasaki's Disease
}

\author{
Vijay R. Karia $\cdot$ George C. Hescock • \\ Abraham Gedalia $\cdot$ Nancy Ross-Ascuitto
}

Published online: 30 October 2010

(C) Springer Science+Business Media, LLC 2010

\section{Erratum to: Pediatr Cardiol}

DOI 10.1007/s00246-010-9781-y

The original version of this article unfortunately contained a mistake. The name of one of Authors [Abraham Gedelia] was incorrect. The correct name is Abraham Gedalia.

The online version of the original article can be found under doi:10.1007/s00246-010-9781-y.

V. R. Karia · A. Gedalia

Department of Rheumatology, Louisiana State University

Health Sciences Center, 200 Henry Clay Avenue,

New Orleans, LA 70118, USA

G. C. Hescock

Department of Pediatrics, Louisiana State University

Health Sciences Center, 200 Henry Clay Avenue,

New Orleans, LA 70118, USA

N. Ross-Ascuitto $(\square)$

Department of Pediatric Cardiology, Louisiana State University

Health Sciences Center, 200 Henry Clay Avenue,

New Orleans, LA 70118, USA

e-mail: nrossascuitto@yahoo.com 